\title{
SERMs in the prevention and treatment of postmenopausal osteoporosis: an update
}

\author{
SERMs na prevenção e no tratamento da osteoporose \\ pós-menopausa: uma atualização
}

Jaime Kulak Júnior', Carolina Aguiar Moreira Kulak², Hugh S. Taylor ${ }^{3}$

${ }^{1}$ Serviço de Tocoginecologia, Hospital de Clínicas, Universidade Federal do Paraná (UFPR), Curitiba, PR, Brasil

${ }^{2}$ Serviço de Endocrinologia e Metabologia (SEMPR), Hospital de Clínicas, UFPR, Curitiba, PR, Brasil ${ }^{3}$ Departamento de Obstetrícia, Ginecologia e Ciências de Reprodução, Yale University School of Medicine, New Haven, CT, United States

\author{
Correspondence to: \\ Jaime Kulak Júnior \\ Rua General Carneiro, 180 \\ $6^{\circ}$ andar \\ 80060-150 - Curitiba, PR, Brasil \\ jkulak@ufpr.br
}

Received on Nov/30/2009

Accepted on Feb/9/2010

\section{SUMMARY}

Selective estrogen receptor modulators (SERMs) have the ability to bind the estrogen receptor (ER) and are known to confer ER agonist or antagonist effects depending on the target tissue. A number of newer SERMs, including bazedoxifene, lasofoxifene and ospemifene, are currently under clinical development for the prevention and treatment of postmenopausal osteoporosis and for other indications. Although the possibility of developing a single agent that has all of the desired characteristics of an ideal SERM seems to be unlikely, progress in the clinical development of SERMs targeted to the ER suggests that these newer compounds may have attributes that represent an improvement relative to existing SERMs. A new approach to menopausal therapy is the tissue selective estrogen complex or the pairing of a selective estrogen receptor modulator with estrogens. Further investigation will help to clarify relative benefits/risks of novel SERMs in development within specific indications. Arq Bras Endocrinol Metab. 2010;54(2):200-5

\section{Keywords}

Selective estrogen receptor modulator (SERM); menopause; estrogens; osteoporosis; tissue selective estrogen complex (TSEC)

\section{SUMÁRIO}

Moduladores seletivos do receptor do estrogênio (SERMs) têm a habilidade de se ligar ao receptor de estrogênio (ER) e são conhecidos por conferir um efeito agonista ou antagonista sobre o tecido-alvo. Um número de novos SERMs, incluindo bazedoxifeno, lasofoxifeno e ospemifeno, está atualmente em desenvolvimento clínico para prevenção e tratamento da osteoporose pós-menopausa e para outras indicações. Embora a possibilidade de desenvolver um simples agente que tenha todas as características desejadas de um SERM ideal parece ser pouco provável, esses novos SERMs apresentam propriedades que indicam uma melhora em relação aos SERMs existentes. Uma nova opção terapêutica é o uso do complexo estrogênico do tecido seletivo ou a associação do SERM com estrogênios. Novos estudos ajudarão a rastrear os riscos e benefícios dos novos SERMs em desenvolvimento dentro das suas indicações específicas. Arq Bras Endocrinol Metab. 2010;54(2):200-5

\section{Descritores}

Moduladores específicos dos receptores de estrogênio (SERM); menopausa; estrogênio; osteoporose; complexo estrogênico do tecido seletivo (TSEC)

\section{INTRODUCTION}

$\mathrm{P}$ ostmenopausal osteoporosis is an asymptomatic skeletal disease that is often underdiagnosed and undertreated. Adequate intake of calcium and vitamin D is recommended as baseline therapy for osteoporosis prevention and treatment. Available pharmacological agents for the management of postmenopausal osteoporosis may not be appropriate for all women. Selective estrogen receptor modulator (SERM) refers to a structurally diverse group of compounds that bind to the estrogen receptor (ER) and confer mixed functional ER agonist or antagonist activity depending on the target 
tissue. Conceptually, an ideal SERM would have ER agonist activity in tissues where mimicking the action of estrogens is desirable (e.g., skeletal, cardiovascular, and central nervous systems), and ER neutral or antagonist activity in tissues estrogens have been shown to adversely stimulate (e.g., breast and endometrium) (1). Despite the lack of an ideal SERM to date, a number of SERMs have demonstrated a favorable benefit-risk balance within specific therapeutic indications. Newer SERMs are currently undergoing clinical investigation for the management of postmenopausal conditions associated with estrogen deficiency, particularly osteoporosis. This update describes the most recent literature on SERMs to evaluate their safety and efficacy on the treatment of postmenopausal osteoporosis. It should be noted that the US Food and Drug Administration (FDA) recently replaced the term "SERM" with "estrogen agonist/ antagonist drug"; however, in this review, the term "SERM" will be used throughout the article.

\section{THE PROMISE OF SERMS}

SERMs are known to bind to ERs with high affinity and to mediate transcriptional events (2). The promise of SERMs lies in their ability to differentially act as ER agonists or antagonists depending on the target tissue (3). The exact mechanisms by which SERMs exert their tissue-specific actions are not totally understood, although evidence suggests that the balance of ER coregulators and the cellular microenvironment interact to determine the effect of a SERM on a given cell type (4). Microarray gene expression analysis has shown that different sets of genes are regulated through ER $\alpha$ versus ER $\beta$ in response to estradiol and SERMs (2). The wide-ranging effects of SERMs seem to be mediated by expression of the ER in different tissues, ER conformation after binding of the ER ligand, and expression and binding of the ER/ligand complex to coregulator proteins (1). SERMs are characterized by their complex pharmacologic effects on ER-regulated signaling pathways rather than a common chemical structure. As a result, SERMs must be evaluated individually because each SERM has unique pharmacologic properties that determines its clinical potential. An ideal SERM shoul prevent bone loss and fractures; reduce the risk of breast and endometrial cancer (and limit endometrial proliferation); provide relief of hot flushes and other menopausal symptoms; and not increase the risk of coronary heart disease, stroke, or deep vein thrombosis (Table 1) (5).
Table 1. Effects of SERMS

\begin{tabular}{lccc}
\hline SERM & $\begin{array}{c}\text { Endometrial } \\
\text { stimulation }\end{array}$ & $\begin{array}{c}\text { Vaginal } \\
\text { maturation }\end{array}$ & Hot flushes \\
\hline Tamoxifen & Yes & No & $\uparrow$ \\
Raloxifene & Yes & No & $\uparrow$ \\
Lasofoxifene & Yes & Yes & $\uparrow$ \\
Ospemifene & Yes & Yes & - \\
Bazedoxifene & No & No & $\uparrow$ \\
\hline
\end{tabular}

\section{CURRENTLY AVAILABLE SERMS}

\section{Tamoxifen}

Tamoxifen has a well known antiestrogen activity in the breast and estrogen-like activity in the uterus (6), and is recognized as a highly effective agent for the treatment of ER-positive breast cancer. Tamoxifen has also been shown to provide skeletal and cardioprotective benefits $(7,8)$; however, endometrial safety concerns limit its use in the postmenopausal population with breast cancer. Tamoxifen is associated with an increased incidence of venous thromboembolic events, vasomotor symptoms, and sometimes stroke $(9,10)$.

\section{Raloxifene}

Raloxifene is the only SERM approved worldwide for the prevention and treatment of postmenopausal osteoporosis and vertebral fractures and it is also indicated for the prevention of breast cancer in postmenopausal women. In postmenopausal women with low or normal bone mineral density (BMD), treatment with raloxifene $60 \mathrm{mg}$ was shown to increase lumbar spine BMD by $2.4 \%$ relative to placebo $(\mathrm{P}<0.001)(11)$. The Multiple Outcomes of Raloxifene Evaluation (MORE) trial found that treatment with raloxifene 60 and $120 \mathrm{mg} /$ day for 3 years significantly reduced vertebral fracture risk by $30 \%$ (relative risk, $0.7 ; 95 \% \mathrm{CI}, 0.5-0.8$ ) and $50 \%$ (relative risk, $0.5 ; 95 \% \mathrm{CI}, 0.4-0.7$ ) compared with placebo, respectively, in postmenopausal women with osteoporosis (12). In the Tamoxifen and Raloxifene trial of more than 19,000 postmenopausal women, raloxifene was shown to be as effective as tamoxifen in reducing the risk of invasive breast cancer (13). Although raloxifene has demonstrated efficacy in vertebral fracture reduction, it has shown no significant effect on the overall risk of nonvertebral fracture $(12,14)$. Post hoc analyses of subgroups of women enrolled in the MORE trial (15) and those who entered the Continuing Outcomes Relevant to Evista trial (16) have shown 
a significant reduction in nonvertebral fracture risk at six common sites (clavicle, humerus, wrist, pelvis, hip, and lower leg) in raloxifene-treated women with severe baseline vertebral fractures.

A statistically significant increase in endometrial thickness $(+0.01 \mathrm{~mm})$ was seen with raloxifene compared with placebo $(+0.27 \mathrm{~mm})$ after 3 years $(\mathrm{P}<0.01$ $v s$. placebo) of therapy in the MORE trial, although there was no increase in the risk of endometrial cancer (17). Venous thromboembolic events occurred in 1.0\% of women who received raloxifene, compared with $0.3 \%$ of women who received placebo (relative risk, 3.1; 95\% CI, 1.5-6.2). Like tamoxifen, raloxifene has been shown to induce or exacerbate vasomotor symptoms in postmenopausal women $(18,19)$. An analysis of eight randomized trials showed a statistically significant increase in the incidence of hot flushes $(\mathrm{P}<0.05)$ with raloxifene relative to placebo $(6.3 \%$ increase $)$ or hormone therapy (estrogen therapy or estrogen/progestogen therapy; $20.6 \%$ and $23.6 \%$ increase, respectively) (20).

\section{NEW SERMS IN DEVELOPMENT}

Several new SERMs have entered clinical development in recent years, but some were discontinued because of unacceptable safety and/or tolerability profiles. For instance, the clinical development of idoxifene and levormeloxifene for postmenopausal osteoporosis was discontinued, in part, because of adverse uterine effects, including increased endometrial thickness $(21,22)$. Progress in the clinical development of novel SERMs is described in the following sections.

\section{Lasofoxifene}

Lasofoxifene has been investigated for the prevention and treatment of osteoporosis and for the treatment of vaginal atrophy in postmenopausal women. In a 2-year, randomized, double-blind study of postmenopausal women $(\mathrm{N}=410)$, the mean change in lumbar spine BMD relative to placebo was significantly greater $(\mathrm{P}<0.05)$ with lasofoxifene 0.25 and $1.0 \mathrm{mg} /$ day (3.6\% and $3.9 \%$, respectively) compared with raloxifene $60 \mathrm{mg}(1.7 \%)$, although the responses were comparable for total hip. Both lasofoxifene and raloxifene significantly reduced levels of bone turnover markers and low-density lipoprotein cholesterol compared with placebo (23). Preliminary clinical data have also shown that treatment with lasofoxifene improves signs and symptoms of vaginal atrophy, including dyspareunia.
The safety and tolerability profile of lasofoxifene seems to be similar to that of raloxifene, although discontinuation rates because of adverse events have been shown to be more common with lasofoxifene (23). Evidence suggests that lasofoxifene treatment may cause increased endometrial thickness compared with placebo, although there has been no evidence of an increased risk of endometrial hyperplasia or cancer (23). The manufacturer of lasofoxifene received a nonapproval letter from the US FDA in September 2005, which cited the need for additional data on safety and benefits on its use as a preventive therapy for osteoporosis. Moreover, lasofoxifene was not approved by the US FDA for the treatment of vaginal atrophy in January 2006.

\section{Ospemifene}

The effects of ospemifene on biochemical markers of bone turnover in postmenopausal women have also been evaluated. In phase 2 studies, ospemifene had a similar effect on most markers of bone resorption and bone formation compared with raloxifene and significantly greater changes from baseline compared with placebo $(\mathrm{P}<0.05)$ at most doses $(24,25)$. A phase 2 study found that ospemifene does not induce vasomotor symptoms in postmenopausal women (25). However, further studies have shown no significant difference between raloxifene and ospemifene in the incidence of hot flushes (26). Evidence suggests that ospemifene may be associated with increased endometrial thickness and uterine volume (27).

\section{Arzoxifene}

Arzoxifene was initially investigated for the treatment and prevention of breast cancer. Promising results were observed in early clinical evaluations, as arzoxifene was shown to decrease proliferation indices in breast carcinoma treated 2 to 6 weeks before resection of the lesion (28). The effects of arzoxifene $20 \mathrm{mg} / \mathrm{d}$ on bone mineral density, fractures, uterine safety, and overall safety were further studied in a randomized, placebocontrolled trial including postmenopausal women with normal to low bone mass (29). However, in August 2009 preliminary results from a five-year clinical study showed that arzoxifene met its primary endpoints of reduction in vertebral fractures and breast cancer in postmenopausal women. However, arzoxifene failed to meet secondary endpoints of reduction in non-vertebral fractures and cardiovascular events and improvements in cognitive function. Based on these results, 
the drug company announced they are discontinuing further development of the drug and would not seek regulatory approval (30).

\section{Bazedoxifene}

Bazedoxifene is in late-stage clinical development for the prevention and treatment of postmenopausal osteoporosis. Bazedoxifene was developed using stringent preclinical selection criteria, including positive effects on bone and lipid metabolism, with a favorable uterine and breast safety profile (31). In phase 2 studies of healthy postmenopausal women, bazedoxifene treatment demonstrated statistically significant reductions in markers of bone remodeling without increasing the incidence of breast pain or evidence of endometrial stimulation (32). Phase 3 trials of bazedoxifene for osteoporosis prevention and treatment have been completed. In a 2-year study of 1,583 postmenopausal women with normal or low BMD, treatment with bazedoxifene was shown to prevent bone loss, whereas placebo-treated women experienced loss of BMD at all skeletal sites (33). Relative to placebo, bazedoxifene 10,20 , and $40 \mathrm{mg} /$ day and raloxifene $60 \mathrm{mg} /$ day significantly increased BMD at the lumbar spine $(1.1 \%, 1.4 \%, 1.5 \%$, and $1.5 \%$, respectively) and total hip $(1.3 \%, 1.8 \%, 1.6 \%$, and $1.7 \%$, respectively; $\mathrm{P}<0.001$ for all comparisons). Bazedoxifene 10, 20, and $40 \mathrm{mg} /$ day and raloxifene $60 \mathrm{mg} /$ day significantly reduced serum levels of osteocalcin $(21 \%, 22 \%, 22 \%$, and $27 \%$, respectively) and C-telopeptide $(25 \%, 24 \%, 22 \%$, and $32 \%$, respectively) from baseline $(\mathrm{P}<0.001 v s$. placebo for all comparisons) and had favorable effects on lipid parameters (total cholesterol, low-density lipoprotein cholesterol, high-density lipoprotein cholesterol).

Most recently, a 3-year study of 7,492 postmenopausal women with osteoporosis showed that the risk of new vertebral fracture was significantly reduced by $42 \%$ (relative risk, $0.58 ; 95 \% \mathrm{CI}, 0.38<0.89$ ), 37\% (relative risk, $0.63 ; 95 \% \mathrm{CI}, 0.42<0.96$ ), and $42 \%$ (relative risk, $0.58 ; 95 \% \mathrm{CI}, 0.38<0.89$ ) with bazedoxifene 20 and $40 \mathrm{mg}$ /day and raloxifene $60 \mathrm{mg} /$ day, respectively, relative to placebo $(\mathrm{P}<0.05$ for all comparisons) $(34)$ There were no differences in the incidence of nonvertebral fractures among groups in the overall population.

In a post hoc analysis of a subgroup of women ( $\mathrm{n}$ $=1,772$ ) at higher risk for fracture based on known skeletal risk factors (femoral neck T-score $\leq-3.0$ and/or $\geq 1$ moderate or $\geq 2$ mild vertebral fractures at baseline), bazedoxifene $20 \mathrm{mg}$ /day showed a statistically significant reduction in the risk of all nonvertebral fractures relative to both placebo (relative risk, $0.50 ; 95 \%$ CI, $0.28<0.90 ; \mathrm{P}=0.02$ ) and raloxifene $60 \mathrm{mg}$ (relative risk, $0.56 ; 95 \% \mathrm{CI}, 0.31<1.01 ; \mathrm{P}=0.05)(34)$.

Bazedoxifene was safe and well tolerated in both phase 3 studies, with overall rates of adverse events not different from those with placebo $(33,34)$. In these studies, bazedoxifene and raloxifene showed a similar incidence of hot flushes (prevention study: range, $18.6 \%<24.1 \%$; treatment study: $12.0 \%<13.0 \%)$ that was higher than that with placebo (prevention study: range, $14.2 \%$; treatment study: $6.3 \%$ ) and is consistent with previous reports of SERMs. The incidence of deep vein thrombosis was similar with bazedoxifene and raloxifene (range, $0.4 \%<0.5 \%$ ) and higher compared with placebo $(0.1 \%)$ in the osteoporosis treatment study $(\mathrm{P}<0.05)(34)$. Bazedoxifene was associated with a favorable endometrial and breast safety profile similar to that of placebo and raloxifene in both phase 3 studies. Endometrial thickness with bazedoxifene remained stable throughout both studies, with no differences from baseline or placebo. There was no evidence of an increased incidence of endometrial hyperplasia or carcinoma with bazedoxifene treatment, and the rates of breast pain and breast cancer were not different compared with placebo.

\section{Tissue Selective Estrogen Complex (TSEC)}

To date, no SERM alone has been able to achieve an ideal balance of ER agonist and antagonist activity for an optimal menopausal therapy. However, it may be possible to achieve optimal results based on the blended tissue-selective activities of a SERM and estrogens in a novel approach termed the tissue-selective estrogen complex. Bazedoxifene in combination with conjugated estrogens $(\mathrm{CE})$ is currently under clinical investigation for the treatment of menopausal symptoms (hot flushes and vulvar vaginal atrophy) showing positive results on both $(35,36)$. To evaluate the efficacy of the tissueselective estrogen complex, bazedoxifene/conjugated estrogens (BZA/CE), for postmenopausal osteoporosis prevention, 3,397 women more than 5 years and 1-5 years postmenopause were enrolled in the Osteoporosis Prevention I and II Substudies, respectively. BZA (10, 20 , or $40 \mathrm{mg})$ with CE $(0.625$ or $0.45 \mathrm{mg})$, raloxifene $(60 \mathrm{mg})$, or placebo was administered daily for 2 years. The primary outcome for both substudies was change in bone mineral density of the lumbar spine; bone mineral density was also measured at the hip. Compared with raloxifene, the percent increase in lumbar spine BMD 
from baseline to month 24 was significantly higher for all BZA/CE treatment groups $(\mathrm{P}<0.05)$ for women $1-5$ years postmenopause. Among women $>5$ years postmenopause, BMD significantly improved relative to raloxifene $(\mathrm{P}<0.05)$ for all BZA/CE doses, except those with BZA $(40 \mathrm{mg})$. In substudy I, total hip BMD was significantly higher $(\mathrm{P}<0.001)$ with all $\mathrm{BZA} / \mathrm{CE}$ doses from baseline to months 12 and 24 compared with the decreases observed with placebo. Compared with raloxifene, mean percent increases in total hip BMD were significantly higher $(\mathrm{P}<0.05)$ from baseline to month 24 with BZA $(10 \mathrm{mg}) / \mathrm{CE}(0.625$ or $0.45 \mathrm{mg})$ and BZA $(20 \mathrm{mg}) / \mathrm{CE}(0.625 \mathrm{mg})$. In substudy II, all BZA/CE doses were significantly higher $(\mathrm{P}<0.01)$ for total hip BMD than with placebo at months 12 and 24, as were all BZA/CE doses for femoral neck BMD, except for BZA $(40 \mathrm{mg}) / \mathrm{CE}(0.45 \mathrm{mg})$ at month 12 . Total hip BMD was significantly better $(\mathrm{P}<0.05)$ than with raloxifene for BZA $(10 \mathrm{mg}) / \mathrm{CE}(0.625$ or $0.45 \mathrm{mg})$, and BZA $(20 \mathrm{mg}) / \mathrm{CE}(0.45 \mathrm{mg})$ at month 24 . In substudy II, at all time points, median percent changes from baseline in serum osteocalcin and C-telopeptide were significantly greater with all BZA/CE doses than with placebo $(\mathrm{P}<$ $0.001)$. It is important to note that no significant differences between BZA/CE groups and placebo were found for myocardial infarction, coronary artery disorder, venous thromboembolism, superficial thrombosis, or phlebitis, and BZA/CE did not increase breast pain compared with placebo (37). Such combination has the potential to provide the benefits of hormone therapy without the need for a progestogen in postmenopausal, symptomatic women with a uterus.

\section{CONCLUSIONS}

The development of novel SERMs targeted to the ER in recent years has led to significant progress in the identification of therapeutic agents for the management of postmenopausal conditions related to estrogen deficiency, particularly osteoporosis. The possibility of designing a single molecule that has all of the desired characteristics of an ideal SERM seems to be unlikely.

The benefits of tamoxifen use probably outweigh the associated risks in women who have already been diagnosed with breast cancer. However, endometrial safety concerns may not outweigh the bone protection offered by SERMs in development for postmenopausal osteoporosis. Raloxifene is currently the only SERM approved for the prevention and treatment of post- menopausal osteoporosis, having demonstrated efficacy in preventing bone loss and fractures, with the added benefit of preventing breast cancer.

Clinical data on newer SERMs in development indicate that these compounds may have attributes that represent an improvement relative to currently available SERMs. Other SERMs have shown promise in treating the symptoms of menopause, such as vaginal atrophy, and are also undergoing investigation as possible agents for the prevention of breast cancer. A common adverse event associated with SERMs to date seems to be an increased incidence of hot flushes and warrants further study to determine clinical relevance. Bazedoxifene has been shown to maintain or increase BMD, reduce bone turnover, and decrease the risk of new vertebral fracture in postmenopausal women without evidence of endometrial or breast stimulation in large, prospective phase 3 studies. In the global placebo- and active-controlled osteoporosis treatment study, bazedoxifene showed a significant reduction in nonvertebral fracture risk in a subgroup of more than 1,700 women at higher risk for fracture relative to both placebo and raloxifene. The TSEC containing BZA/CE had an acceptable endometrial profile, suggesting an alternative to the addition of a progestin to estrogens for endometrial protection. Findings from these trials indicate that a TSEC composed of BZA/CE has an acceptable endometrial safety profile. The beneficial effects of BZA/CE on menopausal symptoms and bone loss as well as the bleeding profile and overall safety data may indicate a suitable option for symptomatic postmenopausal women. Clarification of other safety concerns (i.e., venous thromboembolic events) is needed to appropriately determine the benefit/risk balance of SERMs in development.

Disclosure: no potential conflict of interest relevant to this article was reported.

\section{REFERENCES}

1. Riggs BL, Hartmann LC. Selective estrogen-receptor modulators - Mechanisms of action and application to clinical practice. N Engl J Med. 2003;348(7):618-29.

2. Kian Tee M, Rogatsky I,Tzagarakis-Foster C, Cvoro A, An J, Christy $\mathrm{RJ}$, et al. Estradiol and selective estrogen receptor modulators differentially regulate target genes with estrogen receptors alpha and beta. Mol Biol Cell. 2004;15(3):1262-72.

3. Palacios $\mathrm{S}$. The future of the new selective estrogen receptor modulators. Menopause Int. 2007;13(1):27-34.

4. Smith $\mathrm{CL}, \mathrm{O}^{\prime}$ Malley BW. Coregulator function: a key to understanding tissue specificity of selective receptor modulators. Endocr Rev. 2004;25(1):45-71. 
5. Jordan VC, Gapstur S, Morrow M. Selective estrogen receptor modulation and reduction in risk of breast cancer, osteoporosis, and coronary heart disease. J Natl Cancer Inst. 2001;93(19):1449-57.

6. Fisher B, Costantino JP, Redmond CK, Fisher ER, Wickerham $\mathrm{DL}$, Cronin WM. Endometrial cancer in tamoxifen-treated breast cancer patients: findings from the National Surgical Adjuvant Breast and Bowel Project (NSABP) B-14. J Natl Cancer Inst. 1994;86(7):527-37.

7. Love RR, Mazess RB, Barden HS, Epstein S, Newcomb PA, Jordan VC, et al. Effects of tamoxifen on bone mineral density in postmenopausal women with breast cancer. $\mathrm{N}$ Engl J Med. 1992;326(13):852-6.

8. Christodoulakos GE, Lambrinoudaki IV, Botsis DC. The cardiovascular effects of selective estrogen receptor modulators. Ann NY Acad Sci. 2006;1092:374-84.

9. SaphnerT, Tormey DC, Gray R. Venous and arterial thrombosis in patients who received adjuvant therapy for breast cancer. J Clin Oncol. 1991;9(2):286-94.

10. Dignam JJ, Fisher B. Occurrence of stroke with tamoxifen in NSABP B-24. Lancet. 2000;355(9206):848-9.

11. Delmas PD, Bjarnason NH, Mitlak BH, Ravoux AC, Shah AS, Huster WJ, et al. Effects of raloxifene on bone mineral density, serum cholesterol concentrations, and uterine endometrium in postmenopausal women. N Engl J Med. 1997;337(23):1641-7.

12. Ettinger B, Black DM, Mitlak BH, Knickerbocker RK, Nickelsen T, Genant HK, et al. Reduction of vertebral fracture risk in postmenopausal women with osteoporosis treated with raloxifene: results from a 3-year randomized clinical trial. Multiple Outcomes of Raloxifene Evaluation (MORE) Investigators. JAMA. 1999;282(7):637-45.

13. Vogel VG, Costantino JP, Wickerham DL, Cronin WM, Cecchini RS, Atkins $\mathrm{JN}$, et al. Effects of tamoxifen vs. raloxifene on the risk of developing invasive breast cancer and other disease outcomes: the NSABP Study of Tamoxifen and Raloxifene (STAR) P-2 trial. JAMA. 2006;295(23):2727-41.

14. Delmas PD, Ensrud KE, Adachi JD, Harper KD, Sarkar S, Gennari $\mathrm{C}$, et al. Efficacy of raloxifene on vertebral fracture risk reduction in postmenopausal women with osteoporosis: four-year results from a randomized clinical trial. J Clin Endocrinol Metab. 2002;87(8):3609-17.

15. Delmas PD, Genant HK, Crans GG, Stock JL, Wong M, Siris E, et al. Severity of prevalent vertebral fractures and the risk of subsequent vertebral and nonvertebral fractures: results from the MORE trial. Bone. 2003;33(4):522-32.

16. Siris ES, Harris ST, Eastell R, Zanchetta JR, Goemaere S, DiezPerez A, et al. Skeletal effects of raloxifene after 8 years: results from the continuing outcomes relevant to Evista (CORE) study. J Bone Miner Res. 2005;20(9):1514-24.

17. Cummings SR, Eckert S, Krueger KA, Grady D, Powles TJ, Cauley $\mathrm{JA}$, et al. The effect of raloxifene on risk of breast cancer in postmenopausal women: results from the MORE randomized trial. Multiple Outcomes of Raloxifene Evaluation. JAMA. 1999;281(23):2189-97.

18. Stovall DW, Utian WH, Gass ML, Qu Y, Muram D, Wong M, et al. The effects of combined raloxifene and oral estrogen on vasomotor symptoms and endometrial safety. Menopause. 2007;14(3 Pt 1):510-7.

19. Cohen FJ, LuY. Characterization of hot flashes reported by healthy postmenopausal women receiving raloxifene or placebo during osteoporosis prevention trials. Maturitas. 2000;34(1):65-73.

20. Davies GC, Huster WJ, LuY, Plouffe L Jr, Lakshmanan M. Adverse events reported by postmenopausal women in controlled trials with raloxifene. Obstet Gynecol. 1999;93(4):558-65.

21. Fleischer AC, Wheeler JE, Yeh IT, Kravitz B, Jensen C, MacDonald B. Sonographic assessment of the endometrium in osteopenic post- menopausal women treated with idoxifene. J Ultrasound Med. 1999;18(7):503-12.

22. Warming L, Christoffersen C, Riis BJ, Stakkestad JA, Delmas PD, Christiansen C. Adverse effects of a SERM (Levormeloxifene). Safety parameters and bone mineral density 12 months after treatment withdrawal. Maturitas. 2003;44(3):189-99.

23. McClung MR, Siris E, Cummings $S$, Bolognese $M$, Ettinger M, Moffett $A$, et al. Prevention of bone loss in postmenopausal women treated with lasofoxifene compared with raloxifene. Menopause. 2006;13(3):377-86.

24. Komi J, Lankinen KS, DeGregorio M, Heikkinen J, Saarikoski S, Tuppurainen $\mathrm{M}$, et al. Effects of ospemifene and raloxifene on biochemical markers of bone turnover in postmenopausal women. J Bone Miner Metab. 2006;24(4):314-8.

25. Komi J, Heikkinen J, Rutanen EM, Halonen K, Lammintausta R, Ylikorkala O. Effects of ospemifene, a novel SERM, on biochemical markers of bone turnover in healthy postmenopausal women. Gynecol Endocrinol. 2004;18(3):152-8.

26. Komi J, Lankinen KS, Harkonen P, DeGregorio MW, Voipio S, Kivinen $\mathrm{S}$, et al. Effects of ospemifene and raloxifene on hormonal status, lipids, genital tract, and tolerability in postmenopausal women. Menopause. 2005;12(2):202-9.

27. Rutanen EM, Heikkinen J, Halonen K, Komi J, Lammintausta R, Ylikorkala O. Effects of ospemifene, a novel SERM, on hormones, genital tract, climacteric symptoms, and quality of life in postmenopausal women: a double-blind, randomized trial. Menopause. 2003;10(5):433-9.

28. Fabian CJ, Kimler BF, Anderson J, Tawfik OW, Mayo MS, Burak WE Jr, et al. Breast cancer chemoprevention phase I evaluation of biomarker modulation by arzoxifene, a third generation selective estrogen receptor modulator. Clin Cancer Res. 2004;10(16):5403-17.

29. Bolognese M, Krege JH, Utian WH, Feldman R, Broy S, Meats DL, et al. Effects of arzoxifene on bone mineral density and endometrium in postmenopausal women with normal or low bone mass. J Clin Endocrinol Metab. 2009;94(7):2284-9.

30. Company ELa. Lilly Reperts on outcome of Phase III of Arzoxifene, press release. 2009.

31. Komm BS, Lyttle CR. Developing a SERM: stringent preclinical selection criteria leading to an acceptable candidate (WAY-140424) for clinical evaluation. Ann NY Acad Sci. 2001;949:317-26.

32. Ronkin S, Northington R, Baracat E, Nunes MG, Archer DF, Constantine $\mathrm{G}$, et al. Endometrial effects of bazedoxifene acetate, a novel selective estrogen receptor modulator, in postmenopausal women. Obstet Gynecol. 2005;105(6):1397-404.

33. Miller PD, Chines AA, Christiansen C, Hoeck HC, Kendler DL, Lewiecki EM, et al. Effects of bazedoxifene on BMD and bone turnover in postmenopausal women: 2-yr results of a randomized, double-blind, placebo-, and active-controlled study. J Bone Miner Res. 2008;23(4):525-35.

34. Silverman SL, Christiansen C, Genant HK, Vukicevic S, Zanchetta $J R$, de Villiers TJ, et al. Efficacy of bazedoxifene in reducing new vertebral fracture risk in postmenopausal women with osteoporosis: results from a 3-year, randomized, placebo-, and activecontrolled clinical trial. J Bone Miner Res. 2008;23(12):1923-34.

35. Archer DF, Lewis V, Carr BR, Olivier S, Pickar JH. Bazedoxifene/ conjugated estrogens (BZA/CE): incidence of uterine bleeding in postmenopausal women. Fertil Steril. 2009;92(3):1039-44.

36. Archer DF, Pinkerton JV, Utian WH, Menegoci JC, de Villiers TJ, Yuen CK, et al. Bazedoxifene, a selective estrogen receptor modulator: effects on the endometrium, ovaries, and breast from a randomized controlled trial in osteoporotic postmenopausal women. Menopause. 2009 Jun 10.

37. Lindsay R, Gallagher JC, Kagan R, Pickar JH, Constantine G. Efficacy of tissue-selective estrogen complex of bazedoxifene/conjugated estrogens for osteoporosis prevention in at-risk postmenopausal women. Fertil Steril. 2009;92(3):1045-52. 